\title{
EFFECT OF ULTRAVIOLET PHOTOFUNCTIONALISATION ON THE CELL ATTRACTIVENESS OF ZIRCONIA IMPLANT MATERIALS
}

\author{
T. Tuna ${ }^{1 *}$, M. Wein ${ }^{2}$, B. Altmann ${ }^{2}$, T. Steinberg ${ }^{2}$, J. Fischer ${ }^{3}$ and W. Att ${ }^{1,4}$ \\ ${ }^{1}$ Department of Prosthodontics, School of Dentistry, Albert-Ludwigs University of Freiburg, Freiburg 79106, \\ Germany. \\ ${ }^{2}$ Department of Oral Biotechnology, School of Dentistry, Albert-Ludwigs University of Freiburg, Freiburg 79106, \\ Germany. \\ ${ }^{3}$ Institute for Dental Materials and Engineering, University Hospital for Dental Medicine, University of Basel, \\ 4056 Basel, Switzerland. \\ ${ }^{4}$ Department of Restorative Dentistry, Dubai School of Dental Medicine, Dubai, UAE.
}

\begin{abstract}
Ultraviolet (UV) light treatment of implant surfaces has been demonstrated to enhance their bioactivity significantly. This study examined the effect of UV treatment of different zirconia surfaces on the response of primary human alveolar bone-derived osteoblasts (PhABO). Disks of two zirconia-based materials with two different surface topographies (smooth, roughened) were exposed to UV light. Qualitative and quantitative assessment of PhABO on zirconia surfaces, by means of immunofluorescence, scanning electron microscopy and DNA quantification at 4 and $24 \mathrm{~h}$ revealed a higher number of initially attached osteoblasts on UV-treated surfaces. Cell area and perimeter were significantly larger on all UV-treated surfaces $(p<0.05)$. The proliferation activity was significantly higher on both roughened UV-treated surfaces than on untreated samples at day 3 of culture $(p<0.05)$. The expression levels of collagen I, osteopontin and osteocalcin at day 14 and alkaline phosphatase activity at day 7 and 14 of culture period were similar among UV-treated and untreated surfaces. Alizarin-Red-Staining at day 21 demonstrated significantly more mineralised nodules on UV-treated samples than on untreated samples. Contact angle measurements and $\mathrm{X}$-ray photoelectron spectroscopy showed that UV light transformed zirconia surfaces from hydrophobic to (super-) hydrophilic $(p<0.05)$ and significantly reduced the atomic percentage of surface carbon. The results showed that UV light pre-treatment of zirconia surfaces changes their physicochemical properties and improves their attractiveness against $\mathrm{PhABO}$, primarily demonstrated by an augmented cell attachment and spreading. This may result in faster healing and better bone-to-implant contact of zirconia implants in vivo following such a pre-treatment.
\end{abstract}

Keywords: Implant surface, primary human alveolar bone-derived osteoblasts (PhABO), zirconia, ultraviolet, cell culture.

*Address for correspondence:

Dr. med. dent. Taskin Tuna

Department of Prosthodontics, School of Dentistry

Albert-Ludwigs University of Freiburg

Hugstetter Strasse 55, Freiburg 79106, Germany

Phone: +49 (0) 76127049060

Fax: +49 (0) 76127049250

E-mail: ttuna@ukaachen.de

\section{Introduction}

The topographic and physicochemical properties of implant surfaces play a fundamental role in the process of osseointegration (Shalabi et al., 2006).

Today, it is well known that so-called microroughened titanium implant surfaces give rise to a particular fibrin retention that allows osteogenic cells to migrate to the implant surface, enhance the expression pattern of osteoblastic genes and provide rapid maturation of osteoblasts and faster mineralisation of the extracellular matrix (Ogawa et al., 2000). In addition, microroughened implant surfaces show an increased percentage of bone-toimplant contact and require higher forces to break implantbone anchorage than implants with smooth surfaces (Ogawa et al., 2000; Shalabi et al., 2006). Consequently, many additive and subtractive techniques were introduced to alter the surface topography of implants, such as oxidising, sandblasting, acid etching or combinations of these techniques with the ultimate goal to enhance periimplant osteogenesis (Ogawa et al., 2000; Shalabi et al., 2006).

In addition to titanium, the biomedical-grade zirconia is considered as an alternative material for the fabrication of implants (Hisbergues et al., 2009; Ozkurt and Kazazoglu, 2011). This is because of its favourable optical and mechanical properties as well as biocompatibility (Hisbergues et al., 2009). Currently, yttria-stabilised zirconia, also known as tetragonal zirconia polycrystal (Y-TZP), is the most-used material combination for the fabrication of zirconia-based dental implants. Several studies have shown that zirconia implants manifest a similar osseointegration when compared to titanium (Kohal et al., 2009; Sennerby et al., 2005). Although long-term data are still lacking, zirconia implants are being recommended today for patients requesting a metal-free treatment (Hisbergues et al., 2009; Ozkurt and Kazazoglu, 2011). Thus, surface modification techniques of zirconia implants have gained a significant interest. In this context, surface modification of zirconia is considered more difficult than titanium. This is because zirconia does not react to modifying agents, namely acids, in the same manner as titanium (Hisbergues et al., 2009). In addition, other surface treatments of zirconia, such as sandblasting, have been reported to induce the transformation of metastable tetragonal zirconia to the monoclinic phase and generate surface cracking, thereby leading to material property degradation (Ozkurt and Kazazoglu, 2011). 
Despite significant advancements in modification techniques of implant surfaces, it is still not known why bone-titanium implant contact (BIC) remains around $45 \pm 16 \%$ (Weinlaender et al., 1992) or $50 \%$ to $75 \%$ (Ogawa and Nishimura, 2003), which is far below the ideal $100 \%$. In fact, it has been demonstrated that the bone mass around roughened titanium implant surfaces is smaller than that around machined surfaces, mainly due to the diminished proliferative activity of osteoblasts (Bachle and Kohal, 2004; Takeuchi et al., 2005a). In addition, recent findings about the time-dependent alteration property of titanium implant surfaces have proposed a new understanding in the science and knowledge about the bioactivity of implant surfaces. In this phenomenon, termed as biological ageing of implant surfaces, the unavoidable progressive contamination of the implant surface with carbons over time has been demonstrated to be associated with a significant alteration of the protein adsorption capacity as well as cell attachment (Att et al., 2009a; Att et al., 2009b). Consequently, the alteration yields significant reduction in the osseointegration capability of the implant surface (Att and Ogawa, 2012).

Recently, a series of studies reported the generation of highly cell-attractive and osteoconductive titanium surfaces by ultraviolet (UV) light treatment, also termed UV photofunctionalisation (Aita et al., 2009b; Att et al., 2009a; Iwasa et al., 2010). In brief, UV treatment of titanium surfaces has been shown to significantly enhance protein adsorption as well as attachment, proliferation and differentiation of osteoblasts, as well as mineralisation of extracellular matrix (Aita et al., 2009b; Att et al., 2009a). In addition, UV-treated surfaces yielded nearly $100 \%$ bone-to-titanium implant contact, as opposed to less than $55 \%$ for the untreated titanium surfaces (Aita et al., 2009b; Iwasa et al., 2010). This phenomenon has been attributed to the alteration of the physicochemical properties of the surface upon UV treatment, characterised by the removal of surface carbons, conversion of the surface status from hydrophobic to superhydrophilic and possible conversion of the surface charge (Aita et al., 2009b; Iwasa et al., 2010; Takeuchi et al., 2005b). Such findings were not only limited to titanium surfaces, but also for other implantable materials (Att et al., 2009a; Att et al., 2009c). For instance, significantly enhanced bioactivity on UV-light treated machined zirconia surfaces could be demonstrated (Att et $a l ., 2009 \mathrm{c}$ ). Such a procedure could be an easy approach to maximise osseointegration capacity of zirconia surfaces, without altering their topographic configuration.

In vivo studies with roughened zirconia implant surfaces revealed osseointegration capacities similar to titanium (Hoffmann et al., 2012) and better removal torque results than machined zirconia implant surfaces (Sennerby et al., 2005). In light of these findings, it is of interest to investigate as to how far UV-light treatment can influence the bioactivity of a new type of roughened zirconia. To the authors' knowledge, a number of in vitro studies investigated the effect of UV light treatment on the bioactivity of zirconia-based materials (Altmann et al., 2013; Han et al., 2009; Watanabe et al., 2012; Zhang et al., 2012). However, due to different study designs as well as controversial results, no clear conclusions can be drawn about the effect of UV treatment on zirconia surfaces. In addition, in vitro examinations implementing the same cells involved in clinical conditions, namely primary human osteoblasts, are scarce regarding this topic. Therefore, a study involving these cells would provide more reliable information about the effect of UV photofunctionalisation on the bioactivity of zirconia materials and guide future investigations.

Thus, the aim of this study was to examine the influence of UV-light treatment of different new zirconia-based materials having different topographies on the response of primary human alveolar bone osteoblasts ( $\mathrm{PhABO}$ ).

\section{Materials and Methods}

\section{Zirconia samples, UV light treatment and surface characterisation}

Disks of two biomedical grade zirconia-based materials (Zr1 and $\mathrm{Zr} 2$ ) with smooth $(\mathrm{m})$ or roughened (r) surfaces and $20 \mathrm{~mm}$ in diameter and $1.5 \mathrm{~mm}$ in thickness were used. $\mathrm{Zr} 1$ consisted of the metal oxides $\mathrm{ZrO}_{2}(85.7 \mathrm{wt} \%)$, $\mathrm{Al}_{2} \mathrm{O}_{3}(8.3 \mathrm{wt} \%), \mathrm{Y}_{2} \mathrm{O}_{3}(4.3 \mathrm{wt} \%), \mathrm{La}_{2} \mathrm{O}_{3}(1.7 \mathrm{wt} \%) . \mathrm{Zr} 2$ represented a more conventional yttrium tetragonally stabilised zirconium oxide containing $93 \mathrm{wt} \% \mathrm{ZrO}_{2}$, $5 \mathrm{wt} \% \mathrm{Y}_{2} \mathrm{O}_{3}, 1.9 \mathrm{wt} \% \mathrm{HfO}_{2}$ and $0.1 \mathrm{wt} \% \mathrm{Al}_{2} \mathrm{O}_{3}$. The smooth surface of $\mathrm{Zrl}$ was just the as sintered material; the smooth surface of $\mathrm{Zr} 2$ was additionally polished with $3-\mu \mathrm{m}$ diamond paste. The roughened disks were produced by sandblasting with $\mathrm{Al}_{2} \mathrm{O}_{3}$ under a blasting pressure of 6 bar and with a grain size of the blasting media of $105 \mu \mathrm{m}$. The blasting step was followed by acid etching in $38-40 \%$ hydrofluoric acid (HF) for $1 \mathrm{~h}$ and a subsequent thermal treatment step at $1,250{ }^{\circ} \mathrm{C}$ under an oxidative atmosphere with holding time of three hours (Stephan and Schöne, 2012). Before the tests of the present study, all specimens were cleaned with $70 \%$ ethanol and bidistilled water, followed by ultrasonic cleaning in bidistilled water for $5 \mathrm{~min}$ and air-drying. Subsequently, the sterilisation of the specimens was performed by a low-temperature hydrogen peroxide gas plasma sterilisation at $55{ }^{\circ} \mathrm{C}$ (STERRAD $^{\circledR}, 100 \mathrm{NX}^{\mathrm{TM}}$ System, Johnson \& Johnson Medical, Norderstedt, Germany) followed by sealing and storing the disks for one month in the dark (Smith et al., 1991). Half of the disks were treated with UV light for $48 \mathrm{~h}$ under ambient conditions. To facilitate comparison, a similar UV source like in previous studies (Aita et al., 2009b; Att et al., 2009c) was used: a $15 \mathrm{~W}$ bactericidal lamp (Toshiba, Tokyo, Japan), which delivered UV light as a mixture of spectra from a single source of an UVlamp with an intensity of $0.05 \mathrm{~mW} / \mathrm{cm}^{2}(\lambda=360 \mathrm{~nm})$ and $2 \mathrm{~mW} / \mathrm{cm}^{2}(\lambda=250 \mathrm{~nm})$. The seeding of cells onto the UV treated test specimens was performed immediately after UV treatment. Between UV treatment and cell seeding specimens were kept in sterile glass vessels.

Scanning electron microscopy (SEM) (LEO 1525 Field Emission Gun (FEG SEM, Zeiss, Jena, Germany) was used to examine surface morphology of the UVtreated and untreated zirconia disks. Topographical features and surface roughness of each UV-treated and untreated zirconia material were examined by atomic 
force microscopy (AFM) (Nanoscope IIIa, Veeco-Digital Instruments, Santa Barbara, USA). For this, nine different areas on one disk of each material were measured $(n=9)$. Surface wettability of the UV-treated and untreated zirconia disks was examined by contact angle (CA) measurement. The angles of four $1-\mu \mathrm{L} \mathrm{H}_{2} \mathrm{O}$ droplets on a single disk of each material $(n=4)$ were measured (Dataphysics $\mathrm{GmbH}$, Filderstadt, Germany). Electron Spectroscopy for Chemical Analysis (ESCA) was conducted by X-ray photoelectron spectroscopy (XPS) (Perkin Elmer PHI 5600 ESCA System, Physical Electronics, Inc., Chanhassen, Minnesota, USA) under ultra-high vacuum conditions $\left(5 \times 10^{-8} \mathrm{mbar}\right)$ and was used to evaluate surfaces' chemical composition, namely to determine the changes in the elemental content of carbon, oxygen and zirconia after UV-light treatment.

\section{Isolation and cultivation of osteoblasts}

Human osteoblasts were prepared from alveolar bone explants obtained from a healthy adult patient (male, 42 years) during implant placement as previously described (Altmann et al., 2011). The collection of oral bone explants was approved by the Ethics Committee of the Albert-Ludwigs-University, Freiburg, Germany (vote Nr. 411/08). Osteoblasts derived from alveolar bone fragments were cultured in Dulbecco's Modified Eagle's Medium (Low Glucose (1 g/L) (DMEM, PAA Laboratories, Coelbe, Germany) supplemented with $1 \%$ glutamine (GlutaMax $^{\mathrm{TM}}$, Life Technologies, Darmstadt, Germany), $10 \%$ foetal calf serum (Biochrom AG, Berlin, Germany), $10 \mathrm{mM} \mathrm{Na}-\beta$-glycerophosphate, $50 \mu \mathrm{g} / \mathrm{mL}$ ascorbic acid, $0.1 \mu \mathrm{M}$ dexamethasone and $0.2 \%$ kanamycin (SigmaAldrich, Steinheim, Germany). The cells were maintained in a humidified $37{ }^{\circ} \mathrm{C}$ incubator with $5 \% \mathrm{CO}_{2}$. At $80 \%$ confluency cells were detached using $0.1 \%$ trypsin $/ 0.04 \%$ EDTA (Biochrom AG, Berlin, Germany) and seeded at a concentration of $3 \times 10^{4}$ cells $/ \mathrm{cm}^{2}$ onto zirconia disks UV treated for $48 \mathrm{~h}$ or non-treated (Control). The culture medium was renewed every three days. All experiments were carried out with osteoblasts of passage 5 and 6 .

\section{Cell morphology and initial cell attachment}

Cell morphology and initial attachment of PhABO on UV-treated and untreated specimens were examined by scanning electron microscopy (LEO 435VP, Zeiss, Oberkochen, Germany), fluorescence microscopy (Biozero, BZ-9000, Keyence, Neu-Isenburg, Germany) of fluorescent phalloidin-labelled actin and DNA quantification.

For both first tests, osteoblasts on the zirconia disks were rinsed with PBS buffer and fixed in $3.8 \%$ formalin (Carl Roth, Karlsruhe, Germany) after 4 and 24 h culture period.

For scanning electron microscopy (SEM) cell culture specimen were then dehydrated in ascending ethanol series (ranging from 30-100\% ethanol), critical point dried (CPD030 Critical Point Dryer, Bal-Tec AG, Balzers, Liechtenstein) and immediately sputter coated with gold palladium for $60 \mathrm{~s}$ at $60 \mathrm{~mA}$ (SCD050, Balzers, Liechtenstein).

For phalloidin-labelling of the actin cytoskeleton specimens were treated with $0.02 \%$ TritonX-100 (Sigma-
Aldrich, Taufkirchen, Germany) in PBS for $5 \mathrm{~min}$, and incubated with green fluorescent Alexa 488/Phalloidin (1:40, Life Technologies, Darmstadt, Germany) for $40 \mathrm{~min}$. Nuclei were stained with DAPI nucleic acid stain (Life Technologies, Darmstadt, Deutschland) for $15 \mathrm{~min}$. For the assessment of cell morphology and cell number images of representative regions of the cultured specimens were photographed (five images per disc). The cell area and perimeter of altogether 30 randomly picked cells from three disks 4 and $24 \mathrm{~h}$ after seeding were quantified for UVtreated and untreated surfaces using the integrated image analyser tool of the fluorescence microscope (Biozero, BZ-9000, Keyence, Neu-Isenburg, Germany).

For quantification of initial cell attachment on UVtreated and untreated specimens, an indirect evaluation method was applied by measuring the DNA content of the cells attached to the disks after 4 and $24 \mathrm{~h}$ of incubation. After rinsing the adherent cells two times in PBS buffer and lysing them by a freeze-thaw cycle at $-80{ }^{\circ} \mathrm{C}$ in $400 \mu \mathrm{L} \mathrm{TE}$ buffer measurement of the DNA quantity was performed by using a fluorescent nucleic acid staining kit for doublestranded DNA (Quant-iTTM-PicoGreen ${ }^{\circledR}$-dsDNA-AssayKit (Life Technologies, Darmstadt, Germany) according to the manufacturer's instructions. The concentration of fluorescent nucleic acid was measured in a microplate reader (Infinite 200 Pro,Tecan Group Ltd., Switzerland) at $\lambda \mathrm{Ex}=480 \mathrm{~nm}$ and $\lambda \mathrm{Em}=520 \mathrm{~nm}$.

\section{Cell proliferation assay}

Cell proliferation was determined by the alamarBlue ${ }^{\circledR}$ metabolic assay (AbD Serotec, Düsseldorf, Germany). The assay was performed at day 3, 7 and 14 of culture by replacing the culture medium with alamarBlue ${ }^{\circledR}$ reagent. The supernatant was analysed after $2 \mathrm{~h}$ at $37^{\circ} \mathrm{C}$ by measuring fluorescence according to the manufacturer's instructions. Percentage of alamarBlue ${ }^{\circledR}$ reduction in the samples was calculated using a $100 \%$-reduced alamarBlue ${ }^{\circledR}$ control as reference, which was produced according to the manufacturer's protocol.

\section{Gene expression analysis}

Semi-quantitative real-time RT-PCR was used to determine the relative gene expressions of the bone-specific markers collagen type 1 alpha 1 (COL1A1), osteocalcin (BGLAP) and osteopontin (SPP1). At days 7 and 14 of culture, total mRNA of six samples per material and surface $(n=6)$ treatment was pooled, and isolated (RNeasy Mini Kit, Qiagen, Hilden, Germany). The concentration and degradation of mRNA were determined with the Experion Automated Electrophoresis System (Bio-Rad Laboratories, Munich, Germany). Further, a reverse transcription of 400 ng of total RNA was performed using RevertAid ${ }^{\mathrm{TM}}$ First Strand cDNA Synthesis (Fermentas, St. Leon-Rot, Germany). The concentration of cDNA was determined using a Quant-iT ${ }^{\text {MM }}$ PicoGreen ${ }^{\circledR}$ dsDNA Assay Kit (Life Technologies, Darmstadt, Germany). PCR reaction was performed with $5 \mathrm{ng}$ cDNA with a two-step cycling program $\left(1\right.$ cycle: $95{ }^{\circ} \mathrm{C}$ for $10 \mathrm{~min}$; 40 cycles: $95{ }^{\circ} \mathrm{C}$ for $15 \mathrm{~s}$ and $60{ }^{\circ} \mathrm{C}$ for $1 \mathrm{~min}$ ) to detect COL1A1, SPP1 and BGLAP mRNA. The relative mRNA expression was 
normalised with the housekeeping gene GAPDH. The $\triangle \triangle \mathrm{CT}$ analysis was performed with the CFX Manager (Bio-Rad, Munich, Germany).

\section{Measurement of alkaline phosphatase (ALP) activity} Alkaline phosphatase (ALP) activity was determined by the QuantiChrom ${ }^{\text {TM }}$ ALP Kit (BioAssay Systems, Hayward, USA). This assay is based on the ALP-hydrolysis of p-nitrophenyl to the p-nitrophenol, which can be quantified at $405 \mathrm{~nm}$. At days 7 and 14 of culture, cells on zirconia discs were washed twice with PBS buffer, lysed by $500 \mu \mathrm{L}$ Complete Lysis-M Buffer (Roche, Mannheim, Germany) for $10 \mathrm{~min}$ at room temperature and stored at $-20^{\circ} \mathrm{C}$. After thawing the cell lysate, protein concentration in all samples was quantified by the Pierce ${ }^{\circledR} 660 \mathrm{~nm}$ Protein Assay (Thermo, Dreiech, Germany). The alkaline phosphatase activity was determined according to manufacturer's protocol and normalised to $5 \mu \mathrm{g}$ total protein amount for each reaction.

\section{Mineralisation assay}

The mineralisation capacity of cultured osteoblasts was examined with the mineralised nodule area-based AlizarinRed-staining assay. At day 21 of culture, cells were rinsed twice with PBS, fixed with ice cold $100 \%$ ethanol (SigmaAldrich, Taufkirchen, Germany) for $20 \mathrm{~min}$ and rinsed again three times with $\mathrm{ddH}_{2} \mathrm{O}$. The cultures were stained with Alizarin Red solution ( $40 \mathrm{mM}, \mathrm{pH}=4.1)$ for $30 \mathrm{~min}$. The mineralised nodule area was defined as [(stained area/ total disk area) $\times 100)](\%)$ and measured using an image analysis software (Image J, NIH, Bethesda, MD, USA).

\section{Statistical Analysis}

Cell culture experiments, namely alamarBlue ${ }^{\circledR}$, ALP and Alizarin-Red staining were performed in triplicates in three independent experiments $(n=9)$. Data of the measurements of the cell area and perimeter, of the cell culture experiments and the surface roughness parameters of each material were compared for statistically significant differences by using the Student's $t$-test with a significance level of $(p<0.05)$. For contact angle measurements, least squares $(l s)$ means for main effects, all interaction terms and differences of $l s$ means between interaction terms of interest were calculated with their $95 \%$ confidence intervals.

\section{Results}

\section{Surface morphology and hydrophilic properties of UV-treated and untreated zirconia samples}

At $5000 \times$ magnification, the samples showed differently smooth and roughened surface patterns (Fig. 1A). While the smooth surface Zr1-m showed a homogenous submicron porosity containing a high number of fine grainlike pores ranging in size from $50-100 \mathrm{~nm}, \mathrm{Zr} 2-\mathrm{m}$ showed a smooth and flat homogenous surface structure with superficial polishing serrations. The rough surface Zr1-r appeared more compact and had small-sized pits and pores in comparison to $\mathrm{Zr} 2-\mathrm{r}$, which showed a clearly rougher surface with a greater porosity and a greater wavy profile. SEM evaluation revealed no significant changes in the surface properties of all tested materials after UV treatment. Quantitative assessment of the topographic configuration by AFM demonstrated significantly different surface roughness values between the four different surfaces with $\mathrm{R}_{\mathrm{a}}$ values ranging from 0.03-0.3 $\mu \mathrm{m}$ (Fig. 1A). The AFM examination confirmed that UV treatment did not alter the topographical configuration of different samples.

The average contact angles of all untreated surfaces were similar in the range of $56.4^{\circ}$ to $68.8^{\circ}$ with slightly larger contact angles for both smooth surfaces. After UV treatment, the hydrophilic status in all samples changed significantly from hydrophobic to hydrophilic $(p<0.05)$. UV-treated smooth surfaces revealed contact angles between $10-15^{\circ}$, which is 4.5 to 7 times less than untreated surfaces (Fig. 1B). As for roughened UV-treated surfaces the contact angles were less than $6^{\circ}$ (superhydrophilic), i.e. 10 to 20 times less than in the untreated samples (Fig. 1B).

\section{Surface chemistry and the removal of surface carbons by UV treatment}

XPS confirmed that both tested materials mainly contained the elements zirconium ( $\mathrm{Zr}$ ), yttrium (Y) and hafnium (Hf) on their surfaces. In addition, material $\mathrm{Zr} 1$ contained aluminium (Al), lanthanum (La). The $\mathrm{Zr} 3 \mathrm{~d}$ and $\mathrm{Zr} 3 \mathrm{~d} 3 / 2$ peaks were located at about 182 and $185 \mathrm{eV}$, referring to the oxidised $\mathrm{Zr}^{+}$state $\left(\mathrm{ZrO}_{2}\right)$.

The binding energy of the $\mathrm{Y} 3 \mathrm{~d} 3 / 2$ peak at $157.9 \mathrm{eV}$ corresponds both to $\mathrm{Y}_{2} \mathrm{O}_{3}$ and $\mathrm{Y}_{2} \mathrm{O}_{3} /\left(\mathrm{CeOx}+\mathrm{Y}_{2} \mathrm{O}_{3}+\mathrm{ZrO}_{2}\right)$. For material $\mathrm{Zr} 1$, the binding energy of the $\mathrm{Al} 2 \mathrm{p}$ peak at $72.9 \mathrm{eV}$ corresponds to $\mathrm{Al}_{2} \mathrm{O}_{3} / \mathrm{Al}$ and the binding energy of the $\mathrm{La} 3 \mathrm{~d} 5$ peak at $836.0 \mathrm{eV}$ corresponds to $\mathrm{La}_{2} \mathrm{O}_{3}$.

The UV treatment was associated with a significant decrease of surface carbons $(\mathrm{C} 1 \mathrm{~s} / 285 \mathrm{eV})$ by $43-81 \%$, a significant increase of oxygen $(\mathrm{O} 1 \mathrm{~s} / 531 \mathrm{eV})$ by $19-45 \%$ and an increase of zirconia $(\mathrm{Zr} 3 \mathrm{~d} / 182 \mathrm{eV})$ by $9-41 \%$ on all UV-treated surfaces. XPS detail spectra of the smooth and roughened surfaces of the two materials and their changes after $\mathrm{UV}$ treatment for the electrons $\mathrm{C} 1 \mathrm{~s}, \mathrm{O} 1 \mathrm{~s}$ and $\mathrm{Zr} 3 \mathrm{~d}$ are shown in Fig. 1C-E.

\section{Attachment and cell spread of osteoblasts on UV- treated zirconia}

The qualitative evaluation of the fluorescence images clearly revealed improved cell attachment on UV-treated samples compared to untreated disks. Larger cell areas and numbers were obvious on UV-treated zirconia after 4 and $24 \mathrm{~h}$ incubation time (Fig. 2A, Fig. 3A). At $4 \mathrm{~h}$, many osteoblasts on untreated surfaces appeared rounded with only little cytoskeletal development. Morphometric evaluations showed significantly larger values for osteoblast area and perimeter and quantification of cell DNA showed higher amount of cells on UV-treated zirconia surfaces than on untreated samples (Fig. 2B-D). Following $24 \mathrm{~h}$ culture period, a significantly higher number of cells as well as a larger cell spreading area and perimeter was confirmed on all UV-treated surfaces (Fig. 3A-D). The DNA quantification indicated significantly higher cell 


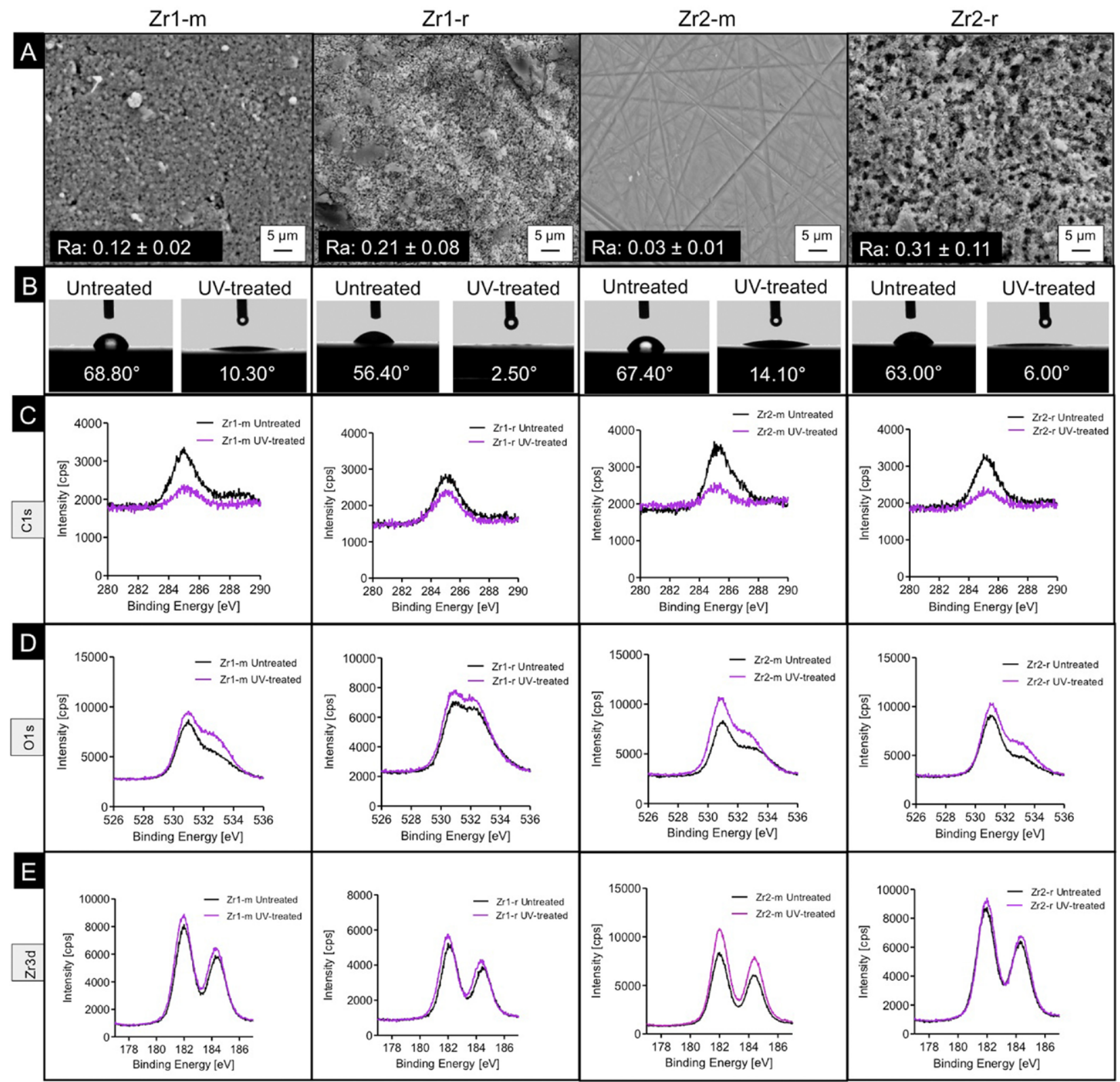

Fig. 1. Surface morphology, hydrophilic property and UV light-induced changes in surface chemistry of zirconia disks. (A) SEM images of the four material surfaces $\mathrm{Zr} 1-\mathrm{m} / \mathrm{r}$ and $\mathrm{Zr} 2-\mathrm{m} / \mathrm{r}$ (mean roughness values (Ra) embedded in the images) (B) Statistically significant conversion from the hydrophobic to hydrophilic status of the zirconia by ultraviolet (UV) light treatment $(p<0.05)$. Representative photographic images of contact angle measurements of $1 \mu \mathrm{L}$ droplets pipetted onto zirconia disks with (UV-treated) or without (untreated) ultraviolet light treatment for $48 \mathrm{~h}$ (mean contact angles are embedded in the contact angle images) (C-E) XPS detail spectra of the smooth and roughened surfaces of the two materials and their changes after UV treatment for the following electrons: $\mathbf{C}$ : C1s; D: O1s; E: Zr3d.

amount on UV-treated specimens after 4 and $24 \mathrm{~h}$. In particular, after $24 \mathrm{~h}$ the difference between treated and untreated specimens depicted an increasing tendency. The findings of the actin cytoskeleton fluorescence microscopy were confirmed by SEM analysis after 4 and $24 \mathrm{~h}$ culture period (Fig. 4A,B).

\section{Proliferation activity}

The alamarBlue ${ }^{\circledR}$ assay showed a general increase of alamarBlue ${ }^{\circledR}$ reduction indicating an increase of the amount of PhABO among all UV-treated and untreated surfaces from 3 to 7 and 7 to 14 days culture period. The tendency of
alamarBlue reduction from day 3 to day 14 was associated with a slightly higher increase on all $\mathrm{Zr} 2$ surfaces $(\mathrm{Zr}-2 \mathrm{~m}$ UV-treated: + $23 \%$; Zr2-m: + $30 \%$; Zr2-r UV-treated: $+26 \%$; Zr2-r: + $41 \%$ ) compared to Zr1 surfaces (Zr-1m UV-treated: + $19 \%$; Zr1-m: + $21 \%$; Zr1-r UV-treated: $+22 \%$; Zr1-r: + $20 \%$ ) (Fig 5A).

While there were no significant differences in the quantity of alamarBlue ${ }^{\circledR}$ reduction between UV-treated and untreated smooth surfaces at any of the three testing times, alamarBlue ${ }^{\circledR}$ reduction on all roughened UVtreated samples was significantly higher than on the untreated roughened samples after a culture period of 3 

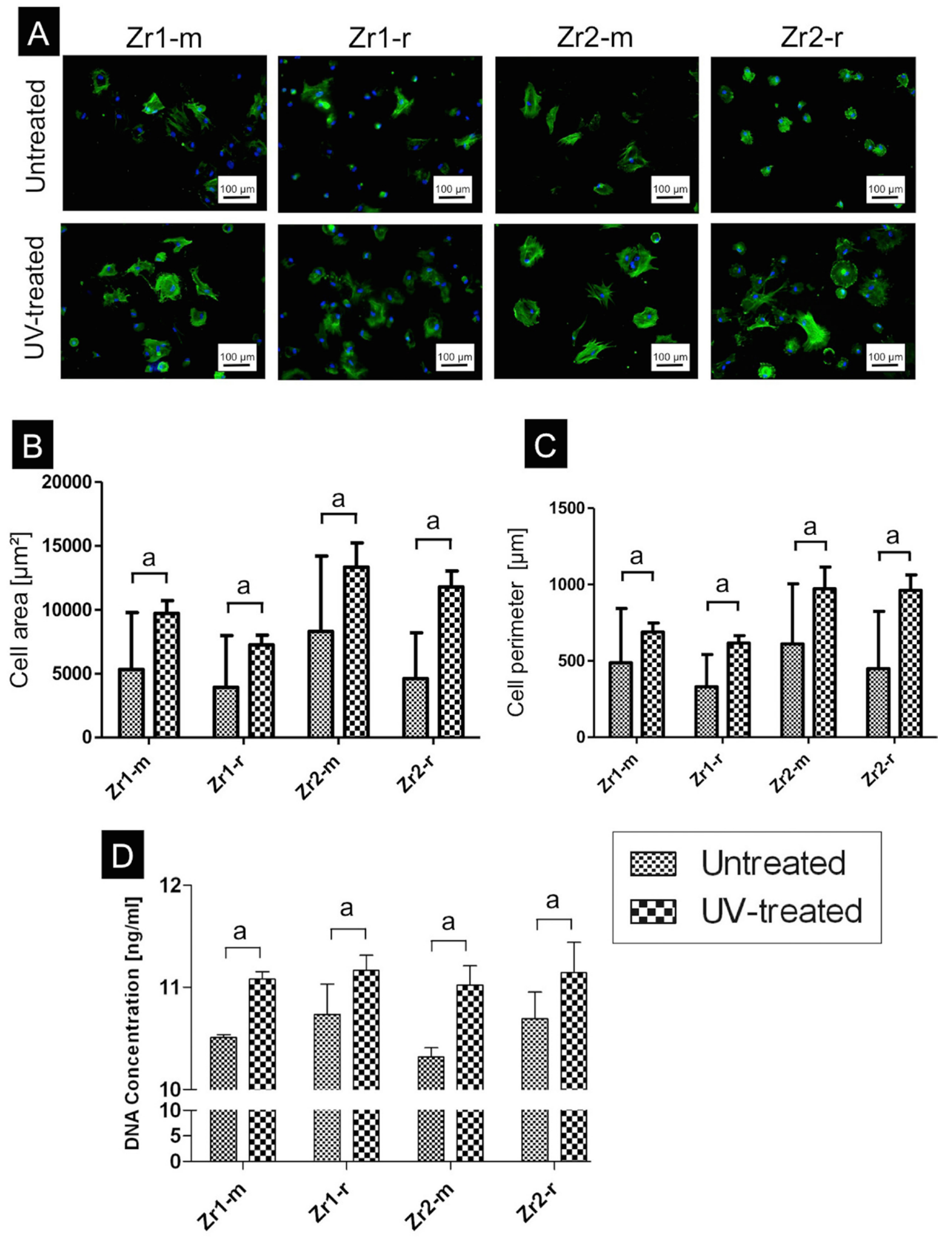

Fig. 2. $4 \mathrm{~h}$ after cell seeding: Initial attachment, cell area and perimeter of osteoblasts on zirconia disks after UV treatment. Initial spread and cytoskeletal arrangement of PhABO $4 \mathrm{~h}$ after seeding onto untreated and UV-treated zirconia surfaces. (A) Representative fluorescence microscopy images of cell cultures with dual staining of DAPI for nuclei (blue) and phalloidin for actin filaments (green) are shown. (B,C) Comparison of the cell area (B) and perimeter (C) development before and after UV treatment of the 4 surfaces after $4 \mathrm{~h}$ of culture. Cell morphometric evaluations were performed using the images. Data are mean $\pm \mathrm{SD}(n=30), p<0.05)$. (D) Indirect quantification of initial cell attachment on UV-treated and untreated specimens by measuring the DNA content of the cells attached to the disks after $4 \mathrm{~h}$ of incubation. Statistical significances with $p<0.05$ are labelled with "a" in the graphs. 

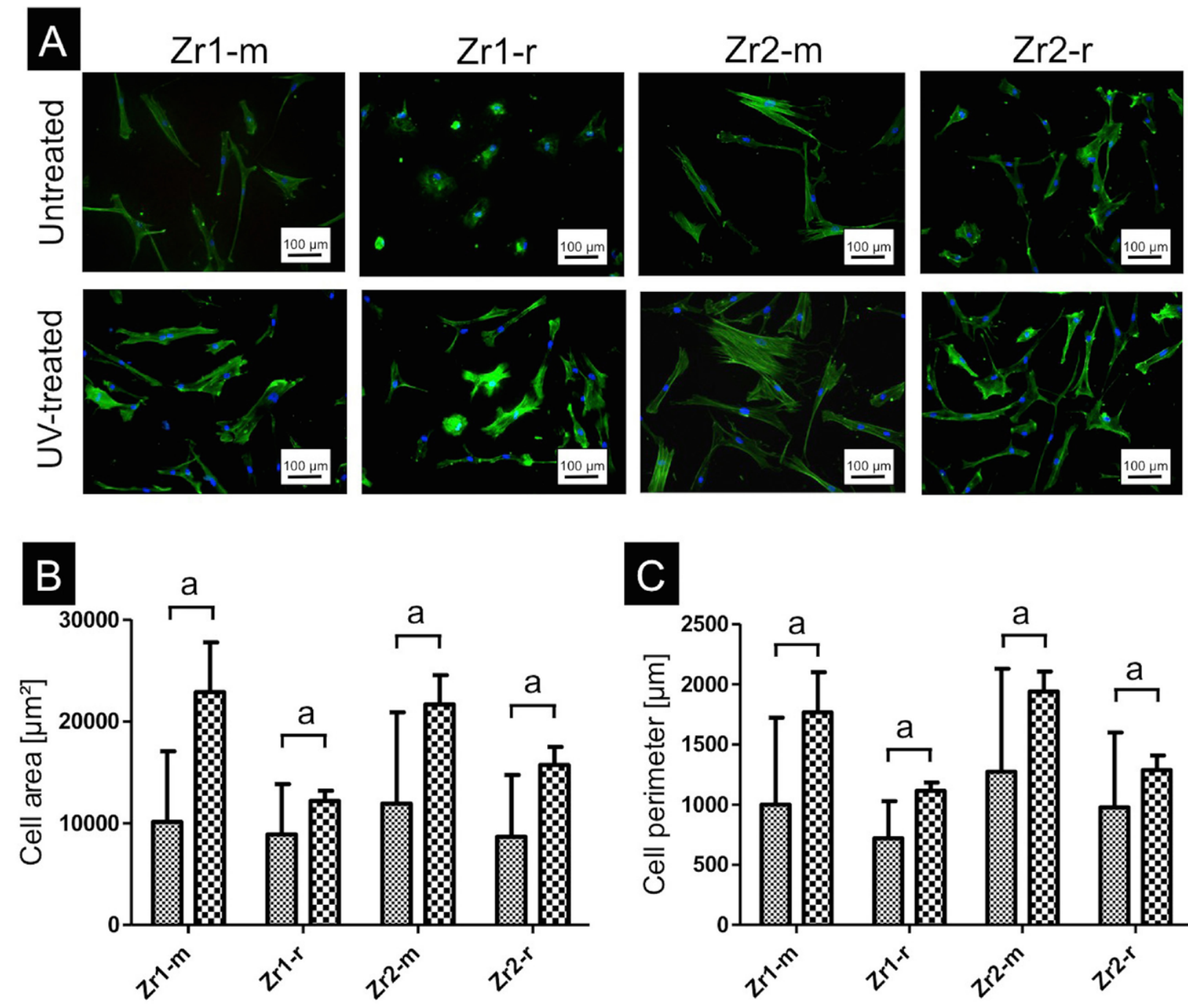

C
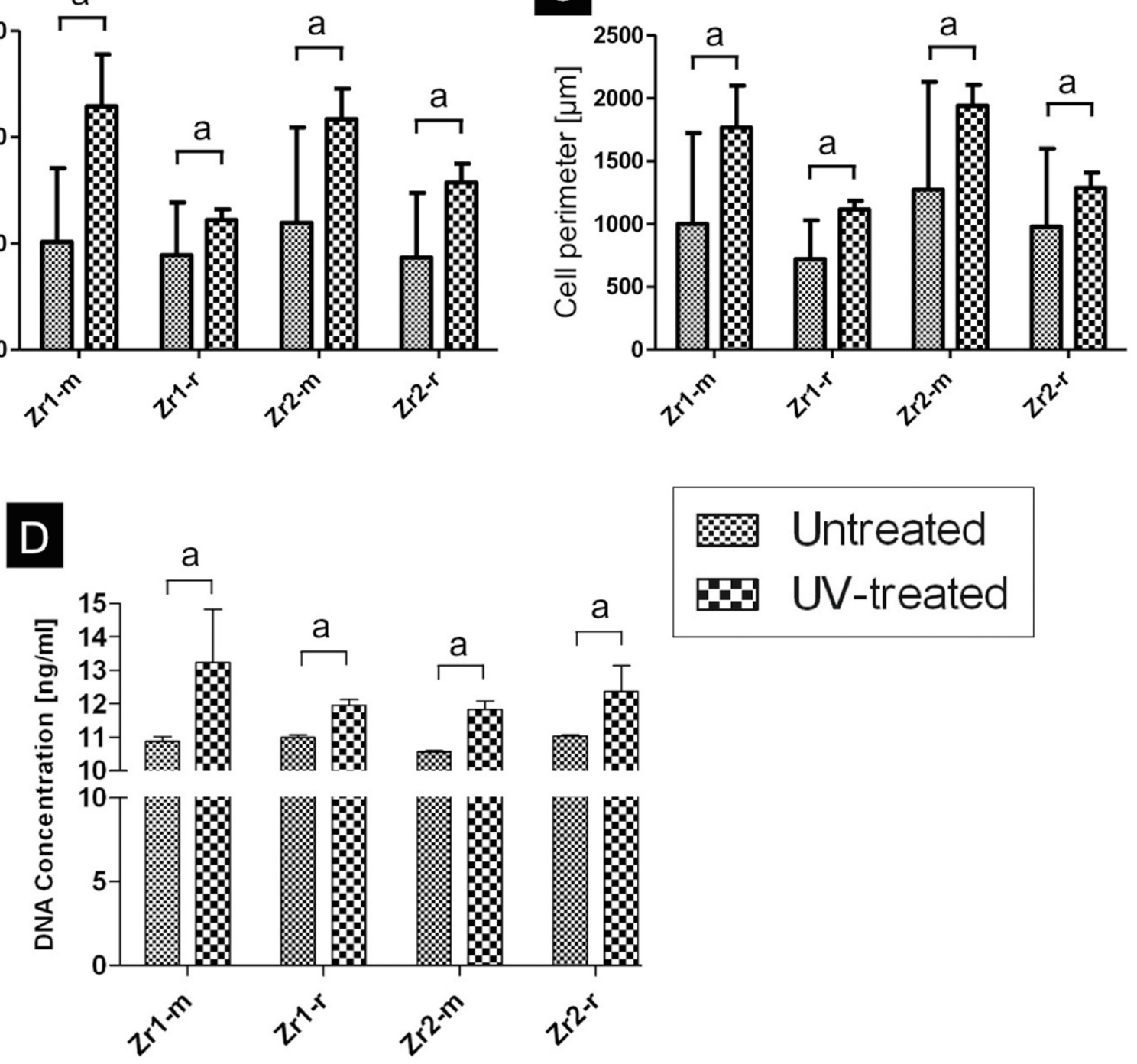

Fig. 3. $24 \mathrm{~h}$ after cell seeding: Initial attachment, cell area and perimeter of osteoblasts on zirconia disks after UV treatment. Initial spread and cytoskeletal arrangement of PhABO $24 \mathrm{~h}$ after seeding onto untreated and UV-treated zirconia surfaces. (A) Representative fluorescence microscopy images of cell cultures with dual staining of DAPI for nuclei (blue) and phalloidin for actin filaments (green) are shown. (B,C) Comparison of the cell area (B) and perimeter (C) development before and after UV treatment of the 4 surfaces after $24 \mathrm{~h}$ of culture. Cell morphometric evaluations were performed using the images. Data are mean $\pm \mathrm{SD}(n=30), p<0.05)$. (D). Indirect quantification of initial cell attachment on UV-treated and untreated specimens by measuring the DNA content of the cells attached to the disks after $4 \mathrm{~h}$ of incubation. Statistical significances with $p<0.05$ are labelled with "a" in the graphs. 

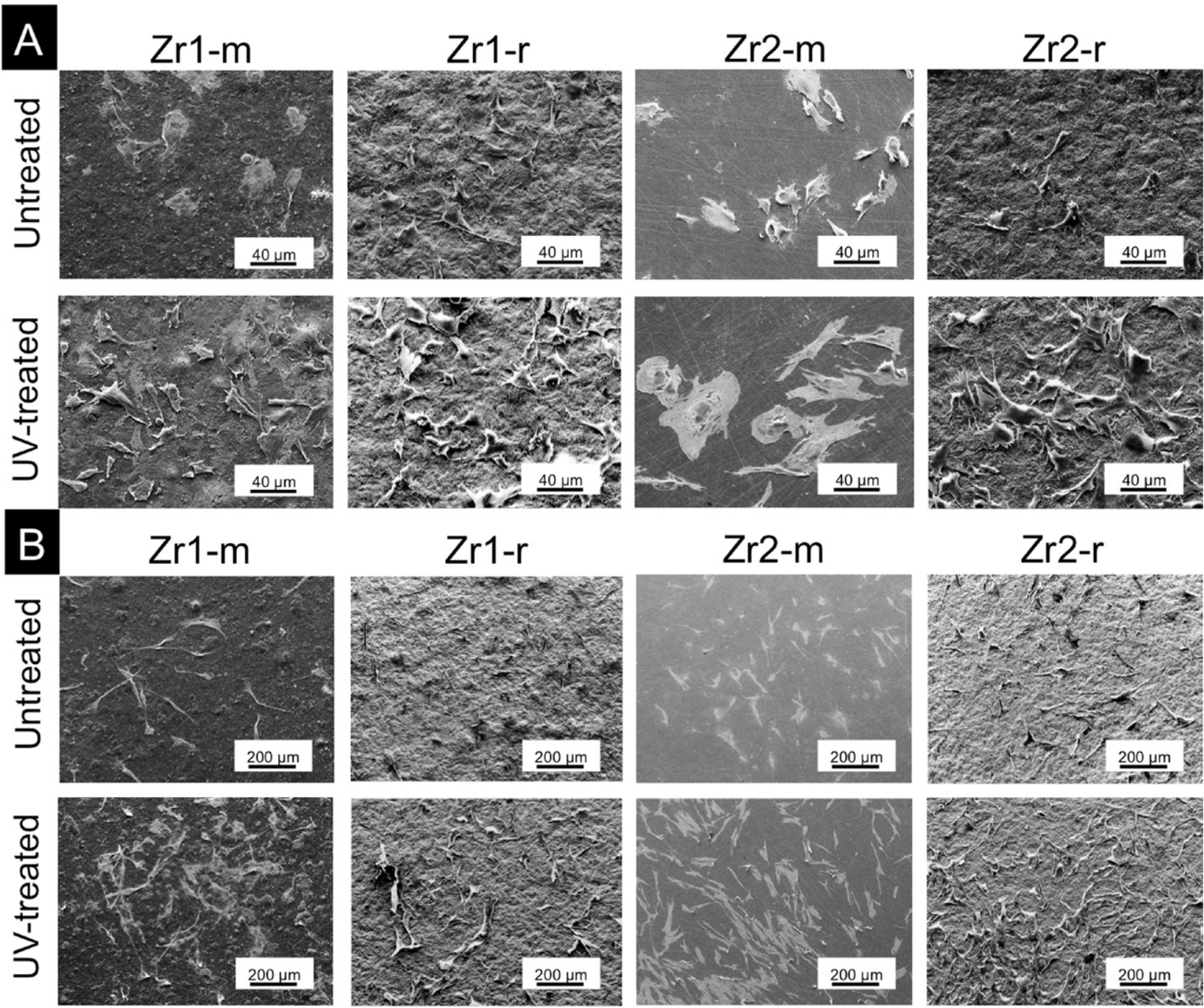

Fig. 4. Morphology, attachment and spreading of osteoblasts on zirconia disks after UV treatment. Representative scanning electron microscope images showing initial spread and cell number of PhABO 4 (A) and $24 \mathrm{~h}(\mathbf{B})$ after seeding onto untreated and UV-treated zirconia surfaces. Cell number on UV-treated surfaces is constantly higher compared to untreated surfaces.

days $(p<0.05)$. However, after 7 days culture period, no differences were found between UV-treated and untreated roughened surfaces and between day 7 and day 14, cells on the untreated Zr2-r surface showed significantly higher proliferation activity than on UV-treated surfaces $(p<0.05)$ (Fig. 5A). Control experiments without seeded cells on all four types of the disks were performed to check if the materials themselves or their components do affect alamarBlue ${ }^{\circledR}$ reduction. However, the results indicated that physicochemical properties of the surfaces alone had no impact on the alamarBlue ${ }^{\circledR}$ assay.

\section{Osteoblast differentiation potential on different zirconia surfaces}

The examination of ALP activity of PhABO after 7 and 14 days culture period yielded no significant differences between UV-treated and untreated surfaces, except for UV-treated Zr2-m surface, where a significantly higher ALP activity was observed at day 7 than on untreated surfaces, and except for UV-treated Zr1-m surfaces, which in contrast to $\mathrm{Zr} 2-\mathrm{m}$ surface revealed significantly lower ALP activity of PhABO at day 7 than on untreated Zr1-m surface. The gene expression analysis of collagen I, osteopontin and osteocalcin was similar among different groups after 14 days culture period (Fig. 5B,C).

The area of mineralised nodules detected by Alizarin red staining after 21 days culture period was larger on all UV-treated samples than on untreated samples. The Alizarin red positive areas were approximately 2.5-3 times larger on UV-treated Zr1 surfaces $(p<0.05)$ and 1.5 times larger on UV-treated Zr2 surfaces $(p<0.05)$ than on untreated samples. (Fig. 6A-C).

\section{Discussion}

The UV treatment of different zirconia materials seems to be a further surface activation method for hard tissue target cell support. The initial behaviour and responses of $\mathrm{PhABO}$ enhanced significantly on UV-treated zirconia surfaces 

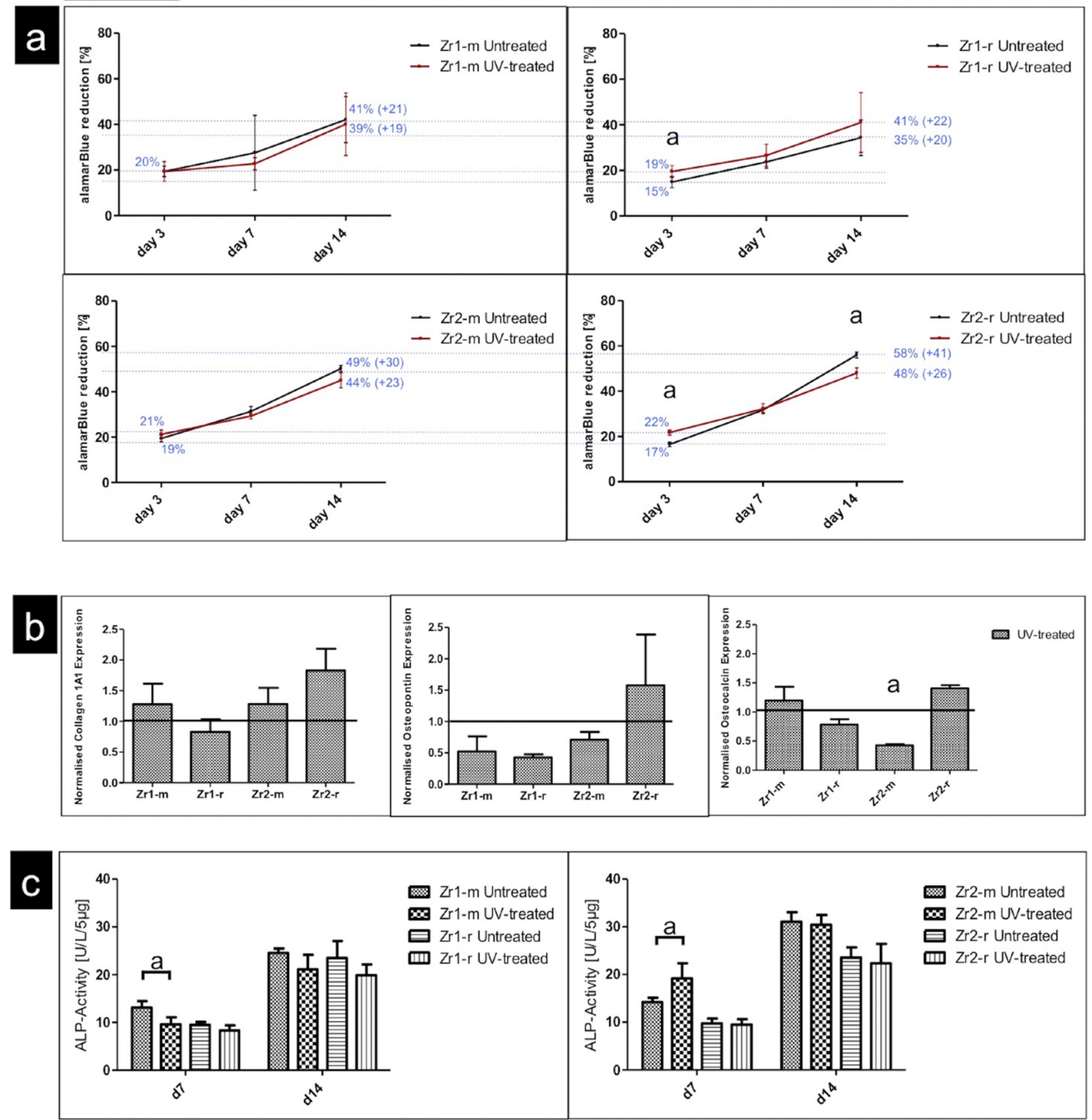

Fig. 5. Proliferation activity and gene expression on UV-treated and non-treated surfaces. (a) Similar alamarBlue reduction values of the cells on untreated and UV-treated surfaces of the 4 materials at day 3, 7 and 14 of culture, except for the initially and significantly higher levels on both UV-treated roughened surfaces at day 3 compared to the untreated roughened Zr-surfaces and except for the significantly higher reduction values on the untreated roughened surface Zr2-r compared to the UV-treated at day 14. For clear illustration of the development of proliferation rates the graphs are labelled with most important percentages at day 3 and day 14. (b) Similar expression levels of collagen I (COL1A1), osteopontin (SPP1) and osteocalcin (BGLAP) on UV-treated and untreated surfaces at day 14 of culture. The relative expression levels were normalised to the housekeeping gene GAPDH. (c) Similarly unchanged Alkaline Phosphatase Activity Assay between UV-treated and untreated groups at day 7 and $14(p<0.05)$. Statistical significances with $p<0.05$ are labelled with "a" in the graphs.

compared to untreated samples. These consequences were evidenced by the following results upon UV treatment: (1) accelerated and augmented cell attachment and (2) accelerated cell spreading and cytoskeletal development. However, except for the mineralised nodule area, proliferation activity, ALP activity and the mRNA expression of osteoblast-specific biomarkers, generally did not change significantly on zirconia surfaces with or without UV treatment.

The observed significant increase in the mineralised nodule area and the alamarBlue ${ }^{\circledR}$ reduction values on UV-treated roughened surfaces at early stages (day 3) compared to the untreated roughened $\mathrm{Zr}$-surfaces seem to be a consequence of an increased quantity of osteoblasts, 


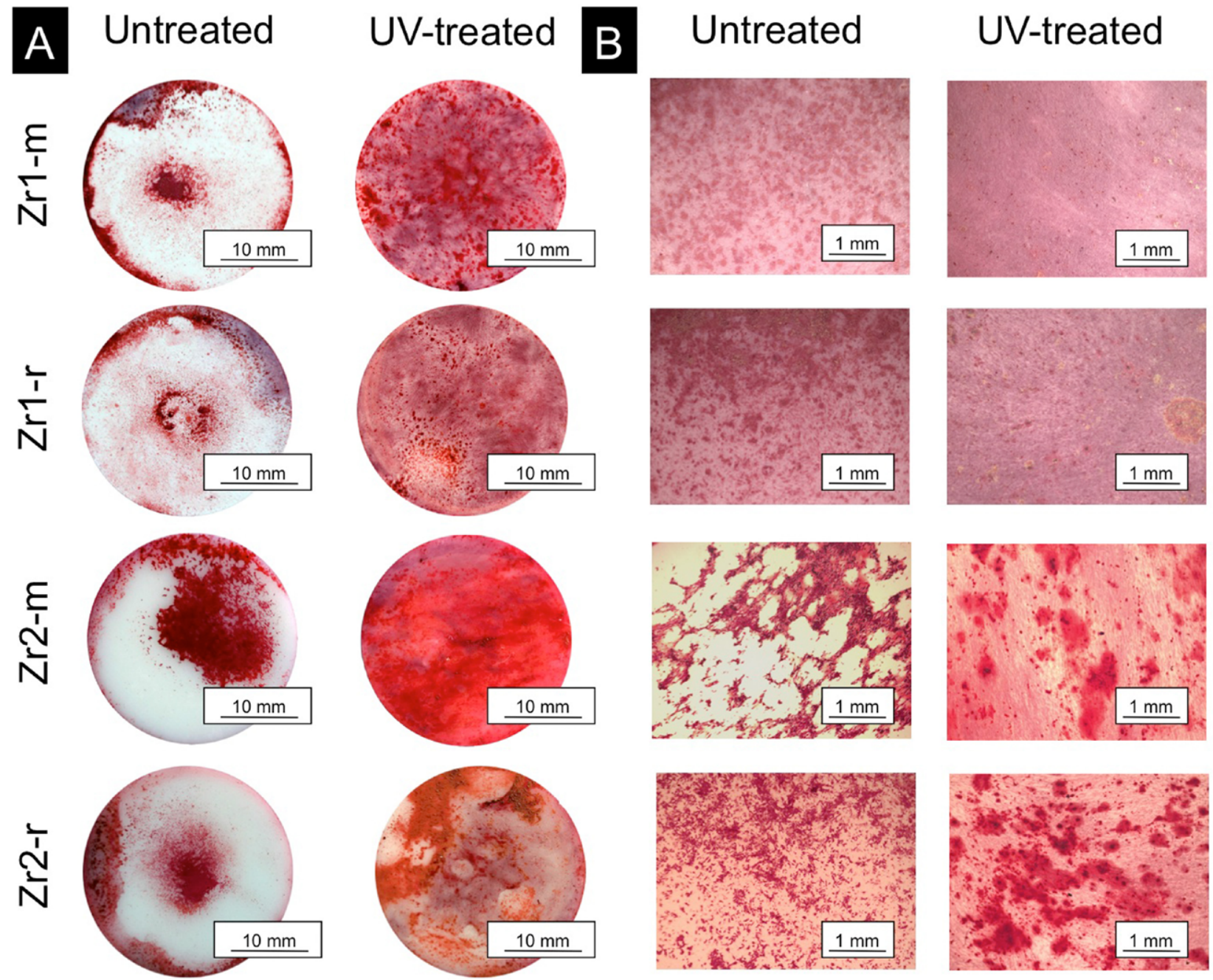

C

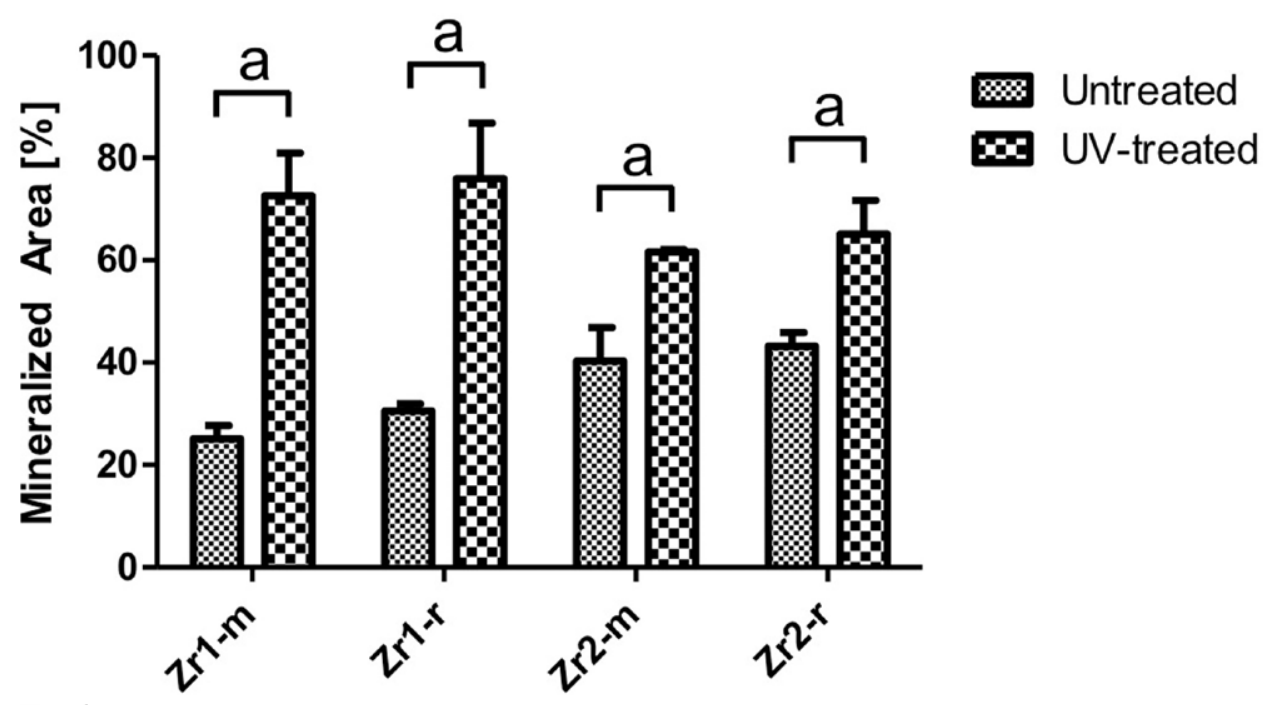

Fig. 6. Mineralisation capacity on UV-treated zirconia. Macro (A) and microscopic (B) images of Alizarin red mineralised nodule staining (ARS) of PhABO cultured on untreated zirconia and $48 \mathrm{~h} \mathrm{UV}$ light-treated zirconia disks for 21 days. The Alizarin red-positive area as a percentage of culture area is shown (histogram) and is statistically significant between the UV-treated and untreated control surfaces $(p<0.05)$. Data are shown as the mean \pm SD $(n=9)$. Statistical significances with $p<0.05$ are labelled with "a" in the graphs. 
which resulted from increased initial cell attachment and distinct cell spreading on the UV-treated zirconia surfaces. In addition, cells on untreated samples seem to cluster in the middle of the untreated samples, which could be associated with less cell attachment on these surfaces.

The effect of UV treatment on the bioactivity of zirconia surfaces has been previously evaluated. UV treatment of a machined zirconia surface increased initial cell attachment and spreading, as well as the osteoblast phenotype of rat bone marrow-derived osteoblasts (Att et al., 2009c). In another study, enhanced initial attachment and an alteration in cell morphologies of mouse osteoblast-like cells MC3T3-E1 were observed on UV-treated sandblasted and acid-etched zirconia surfaces (Watanabe et al., 2012). MAO-coated zirconia surfaces treated with UV light showed a better biocompatibility than untreated MAO surfaces and a comparable proliferation activity (Zhang et al., 2012). In contrast, UV treatment of zirconia and titanium surfaces did not yield an improvement in the response of $\mathrm{PhABO}$ in two other studies (Altmann et al., 2013; Hayashi et al., 2012). However, the latter two studies did not use an osteoblast-differentiation medium for the cell culture, excluding thereby a component needed for proper osteoblast differentiation and matrix mineralisation under in vitro conditions (Coelho and Fernandes, 2000; Eijken et al., 2006). Except for the latter two studies, the overall trend of UV-induced biological enhancement on zirconia is in agreement with previous reports (Att et al., 2009c; Watanabe et al., 2012; Zhang et al., 2012). Nevertheless, the extent to which the behaviour and response of osteoblasts are enhanced seems to be different. This may be attributed to the different surface characteristics of zirconia samples and their UV absorption capacity, as well as to the different types of cells used (Att et al., 2009c; Watanabe et al., 2012). Here, it is well known that cell lines derived from normal healthy tissue (primary cell lines), as they were used in this study, are more difficult to culture in vitro (Anselme et al., 2010). In contrast, permanent cell lines derived from immortalisation of primary cells or from bone tumours show a high proliferation capacity (Anselme et $a l ., 2010)$. Therefore, it is generally recommended that cell phenotypes used for in vitro investigations should resemble as close as possible those used for in vivo investigations (Anselme et al., 2010). The current study, using PhABO, confirms that UV-induced functionalisation for enhanced initial cell attachment and spreading is also obtainable on zirconia surfaces. Further investigations should involve the testing with osteoblasts from different human donors to obtain more representative results.

The photogenerated biological effects, as represented by accelerated and enhanced osteoblast attachment, spread and mineralised nodule area, were associated with the generation of hydrophilicity and the significant reduction of surface carbons. In this study, evidence directly linking the increased hydrophilicity and these biological effects was not obtained. At this stage, the effect of the surface hydrophilicity of biomaterials on their bioactivity is still controversial (Ber et al., 2005; Jansen et al., 2005). It seems to be understandably difficult to obtain consistency of results, and make a conclusion about the direct link between the hydrophilic status of materials and the material's biocompatibility, for the following experimental reasons: (1) the surface topography and composition used, together with the hydrophilicity tested, vary drastically and seem to yield different outcomes, (2) the range of changes in hydrophilicity varies among studies, and (3) different types of cells have been used in different studies and may respond differently. In fact, and in a similar manner to previous studies, the generation of hydrophilicity was not the only physicochemical change that occurred with UV treatment of zirconia (Aita et al., 2009b; Att et al., 2009a). The atomic percentage of hydrocarbon diminished substantially upon UV treatment, whereas the percentage of the other elements uniformly increased according to the reduced occupancy of hydrocarbon (Aita et al., 2009b; Att et al., 2009c).

The UV-induced photocatalytic removal as well as direct decomposition of hydrophobic layers of hydrocarbons and carbonaceous species has been proposed as mechanisms for the generation of highly wettable titanium and machined zirconia (Aita et al., 2009b; Att et al., 2009a; Att et al., 2009c). However, it could also be shown that the level of hydrocarbon, and not hydrophilicity level, strongly correlated with rates of protein adsorption and cell attachment (Aita et al., 2009b). Furthermore, the electrostatic status of UV-treated titanium surfaces has been shown to have a regulatory role in determining their bioactivity, superseding the effect of the hydrophilic property of these surfaces (Iwasa et al., 2010). Here, it should be highlighted that $\mathrm{ZrO}_{2}$ is also a semiconducting photocatalyst material like $\mathrm{TiO}_{2}$. However, UV light having a photon energy larger than $c a .5 \mathrm{eV}$ is required to express photocatalytic activities of zirconia (Wang et al., 2006). On the other hand, progressive accumulation of surface carbons over time on titanium surfaces has been shown to be associated with a conversion of the hydrophilic property from hydrophilic to hydrophobic as well as the change in the electrostatic charge from positive to negative (Att et al., 2009b). These time-dependent physicochemical changes of aged titanium surfaces were associated with significantly less protein and cell attractiveness, resulting in an osseointegration capacity far below that of a newly prepared titanium surface (Att and Ogawa, 2012). In a series of studies, UV-treatment of aged titanium surfaces has been demonstrated to reverse the time-dependent alteration of its bioactivity and to even enhance the surface beyond its innate potential (Att et al., 2009b; Iwasa et al., 2010; Takeuchi et al., 2005b). Although not examined yet, mainly due to the difficulties in surface processing, it can be assumed that zirconia surfaces undergo a time-dependent alteration of their bioactivity similar to that of titanium surfaces (Att et al., 2009c). Studies are needed to explore the possible biological ageing of zirconia.

In conclusion, within the limits of this investigation, UV treatment of roughened zirconia surfaces changed their surface's physical and chemical properties and lead to an enhanced initial cell attachment and cell spreading. The obtained results are more convincing than in previous reports due to the usage of primary human alveolar osteoblasts. However, further investigations using 
osteoblast cells from more than one donor are needed to confirm the results of the present study before further in vivo studies can be performed. In addition, further research is needed to explore the mechanisms by which UV photofunctionalisation acts at the cellular and material's surface level.

\section{Acknowledgements}

The authors would like to thank VITA Zahnfabrik, Bad Säckingen, Germany for funding the study and providing the test samples. Also, the authors thank Dr. med. Dent S. Proksch, Department of Periodontology, University of Freiburg, for the kind support with isolating and characterising the human osteoblasts and to Dr. rer nat. S. Stampf from the Institute of Medical Biometry and Medical Informatics, University of Freiburg for her advice and the execution of the statistical analysis. Finally, the authors thank Prof. M. Swain, Head of Biomaterials Research Unit, United Dental Hospital, University of Sydney, for reviewing the article.

\section{References}

Aita H, Att W, Ueno T, Yamada M, Hori N, Iwasa F, Tsukimura N, Ogawa T (2009a) Ultraviolet lightmediated photofunctionalization of titanium to promote human mesenchymal stem cell migration, attachment, proliferation and differentiation. Acta Biomater 5: 32473257.

Aita H, Hori N, Takeuchi M, Suzuki T, Yamada M, Anpo M, Ogawa T (2009b) The effect of ultraviolet functionalization of titanium on integration with bone. Biomaterials 30: 1015-1025.

Alborzi A, Mac K, Glackin CA, Murray SS, Zernik JH (1996) Endochondral and intramembranous fetal bone development: osteoblastic cell proliferation, and expression of alkaline phosphatase, $\mathrm{m}$-twist, and histone H4. J Craniofac Genet Dev Biol 16: 94-106.

Altmann B, Kohal R-J, Steinberg T, Tomakidi P, Bächle-Haas M, Wennerberg A, Att W (2013) Distinct cell functions of osteoblasts on UV-functionalized titaniumand zirconia-based implant materials are modulated by surface topography. Tissue Eng Part C Methods: 19: 850863.

Altmann B, Steinberg T, Giselbrecht S, Gottwald E, Tomakidi P, Bachle-Haas M, Kohal RJ (2011) Promotion of osteoblast differentiation in 3D biomaterial microchip arrays comprising fibronectin-coated poly(methyl methacrylate) polycarbonate. Biomaterials 32: 8947-8956.

Anselme K, Ponche A, Bigerelle M (2010) Relative influence of surface topography and surface chemistry on cell response to bone implant materials. Part 2: biological aspects. Proc Inst Mech Eng H 224: 1487-1507.

Att W, Hori N, Iwasa F, Yamada M, Ueno T, Ogawa $\mathrm{T}$ (2009a) The effect of UV-photofunctionalization on the time-related bioactivity of titanium and chromium-cobalt alloys. Biomaterials 30: 4268-4276.
Att W, Hori N, Takeuchi M, Ouyang J, Yang Y, Anpo M, Ogawa T (2009b) Time-dependent degradation of titanium osteoconductivity: an implication of biological aging of implant materials. Biomaterials 30: 5352-5363.

Att W, Ogawa T (2012) Biological aging of implant surfaces and their restoration with ultraviolet light treatment: a novel understanding of osseointegration. Int J Oral Maxillofac Implants 27: 753-761.

Att W, Takeuchi M, Suzuki T, Kubo K, Anpo M, Ogawa $\mathrm{T}$ (2009c) Enhanced osteoblast function on ultraviolet light-treated zirconia. Biomaterials 30: 1273-1280.

Bachle M, Kohal RJ (2004) A systematic review of the influence of different titanium surfaces on proliferation, differentiation and protein synthesis of osteoblast-like MG63 cells. Clin Oral Implants Res 15: 683-692.

Ber S, Torun Kose G, Hasirci V (2005) Bone tissue engineering on patterned collagen films: an in vitro study. Biomaterials 26: 1977-1986.

Boyan BD, Bonewald LF, Paschalis EP, Lohmann CH, Rosser J, Cochran DL, Dean DD, Schwartz Z, Boskey AL (2002) Osteoblast-mediated mineral deposition in culture is dependent on surface microtopography. Calcif Tissue Int 71: 519-529.

Coelho MJ, Fernandes MH (2000) Human bone cell cultures in biocompatibility testing. Part II: effect of ascorbic acid, beta-glycerophosphate and dexamethasone on osteoblastic differentiation. Biomaterials 21: 1095 1102.

Eijken M, Koedam M, van Driel M, Buurman CJ, Pols HA, van Leeuwen JP (2006) The essential role of glucocorticoids for proper human osteoblast differentiation and matrix mineralization. Mol Cell Endocrinol 248: 8793.

Ghicov A, Schmuki P (2009) Self-ordering electrochemistry: a review on growth and functionality of $\mathrm{TiO}_{2}$ nanotubes and other self-aligned MOx structures. Chem Commun (Camb) 28 : 2791-2808.

Han Y, Chen D, Sun J, Zhang Y, Xu K (2008) UVenhanced bioactivity and cell response of micro-arc oxidized titania coatings. Acta Biomater 4: 1518-1529.

Han Y, Yan Y, Lu C (2009) Ultraviolet-enhanced bioactivity of $\mathrm{ZrO}$ films prepared by micro-arc oxidation. Thin Solid Films 517: 1577-1581.

Hayashi M, Jimbo R, Lindh L, Sotres J, Sawase T, Mustafa K, Andersson M, Wennerberg A (2012) In vitro characterization and osteoblast responses to nanostructured photocatalytic $\mathrm{TiO}_{2}$ coated surfaces. Acta Biomater 8: 2411-2416.

Hisbergues M, Vendeville S, Vendeville P (2009) Zirconia: Established facts and perspectives for a biomaterial in dental implantology. J Biomed Mater Res B Appl Biomater 88: 519-529.

Hoffmann O, Angelov N, Zafiropoulos GG, Andreana S (2012) Osseointegration of zirconia implants with different surface characteristics: an evaluation in rabbits. Int J Oral Maxillofac Implants 27: 352-358.

Hori N, Att W, Ueno T, Sato N, Yamada M, Saruwatari L, Suzuki T, Ogawa T (2009) Age-dependent degradation of the protein adsorption capacity of titanium. J Dent Res 88: $663-667$. 
Huang S, Chen CS, Ingber DE (1998) Control of cyclin D1, p27(Kip1), and cell cycle progression in human capillary endothelial cells by cell shape and cytoskeletal tension. Mol Biol Cell 9: 3179-3193.

Iwasa F, Hori N, Ueno T, Minamikawa H, Yamada M, Ogawa T (2010) Enhancement of osteoblast adhesion to UV-photofunctionalized titanium via an electrostatic mechanism. Biomaterials 31: 2717-2727.

Jansen EJ, Sladek RE, Bahar H, Yaffe A, Gijbels MJ, Kuijer R, Bulstra SK, Guldemond NA, Binderman I, Koole LH (2005) Hydrophobicity as a design criterion for polymer scaffolds in bone tissue engineering. Biomaterials 26: 4423-4431.

Kohal RJ, Wolkewitz M, Hinze M, Han JS, Bachle M, Butz F (2009) Biomechanical and histological behavior of zirconia implants: an experiment in the rat. Clin Oral Implants Res 20: 333-339.

Mata A, Su X, Fleischman AJ, Roy S, Banks BA, Miller SK, Midura RJ (2003) Osteoblast attachment to a textured surface in the absence of exogenous adhesion proteins. IEEE Trans Nanobioscience 2: 287-294.

Ogawa T, Nishimura I (2003) Different bone integration profiles of turned and acid-etched implants associated with modulated expression of extracellular matrix genes. Int $\mathrm{J}$ Oral Maxillofac Implants 18: 200-210.

Ogawa T, Ozawa S, Shih JH, Ryu KH, Sukotjo C, Yang JM, Nishimura I (2000) Biomechanical evaluation of osseous implants having different surface topographies in rats. J Dent Res 79: 1857-1863.

Ogawa T, Sukotjo C, Nishimura I (2002) Modulated bone matrix-related gene expression is associated with differences in interfacial strength of different implant surface roughness. J Prosthodont 11: 241-247.

Ozkurt Z, Kazazoglu E (2011) Zirconia dental implants: a literature review. J Oral Implantol 37: 367-376.

Sennerby L, Dasmah A, Larsson B, Iverhed M (2005) Bone tissue responses to surface-modified zirconia implants: A histomorphometric and removal torque study in the rabbit. Clin Implant Dent Relat Res 7 Suppl 1: S1320.

Shalabi MM, Gortemaker A, Van't Hof MA, Jansen JA, Creugers NH (2006) Implant surface roughness and bone healing: a systematic review. J Dent Res 85: 496-500.

Shie JL, Lee CH, Chiou CS, Chang CT, Chang CC, Chang CY (2008) Photodegradation kinetics of formaldehyde using light sources of UVA, UVC and UVLED in the presence of composed silver titanium oxide photocatalyst. J Hazard Mater 155: 164-172.

Siddhanti SR, Quarles LD (1994) Molecular to pharmacologic control of osteoblast proliferation and differentiation. J Cell Biochem 55: 310-320.

Smith DC, Pilliar RM, Chernecky R (1991) Dental implant materials. I. Some effects of preparative procedures on surface topography. J Biomed Mater Res 25: 1045-1068.

Stephan M, Schöne A (2012) Ceramic body and process for the preparation thereof; patent number: US 8,257,606 B2. United States Patent.
Takeuchi K, Saruwatari L, Nakamura HK, Yang JM, Ogawa T (2005a) Enhanced intrinsic biomechanical properties of osteoblastic mineralized tissue on roughened titanium surface. J Biomed Mater Res A 72: 296-305.

Takeuchi M, Martra G, Coluccia S, Anpo M (2007) Verification of the photoadsorption of $\mathrm{H}_{2} \mathrm{O}$ molecules on $\mathrm{TiO}_{2}$ semiconductor surfaces by vibrational absorption spectroscopy. J Phys Chem C 111: 9811-9817.

Takeuchi M, Sakamoto K, Martra G, Coluccia S, Anpo M (2005b) Mechanism of photoinduced superhydrophilicity on the $\mathrm{TiO}_{2}$ photocatalyst surface. J Phys Chem B 109: 15422-15428.

Wang R, Hashimoto K, Fujishima A (1997) Lightinduced amphiphilic surfaces. Nature 388: 431-432.

Wang X, Yu JC, Chen Y, Wu L, Fu X (2006) $\mathrm{ZrO}_{2}-$ modified mesoporous nanocrystalline $\mathrm{TiO}_{2}-\mathrm{xNx}$ as efficient visible light photocatalysts. Environ Sci Technol 40: 23692374.

Washburn NR, Yamada KM, Simon CG, Jr., Kennedy SB, Amis EJ (2004) High-throughput investigation of osteoblast response to polymer crystallinity: influence of nanometer-scale roughness on proliferation. Biomaterials 25: $1215-1224$.

Watanabe H, Saito K, Kokubun K, Sasaki H, Yoshinari $M$ (2012) Change in surface properties of zirconia and initial attachment of osteoblastlike cells with hydrophilic treatment. Dent Mater J 31: 806-814.

Weinlaender M, Kenney EB, Lekovic V, Beumer J, 3rd, Moy PK, Lewis S (1992) Histomorphometry of bone apposition around three types of endosseous dental implants. Int J Oral Maxillofac Implants 7: 491-496.

Wong CC, Chu W (2003) The direct photolysis and photocatalytic degradation of alachlor at different $\mathrm{TiO}_{2}$ and UV sources. Chemosphere 50: 981-987.

Woo KM, Seo J, Zhang R, Ma PX (2007) Suppression of apoptosis by enhanced protein adsorption on polymer/ hydroxyapatite composite scaffolds. Biomaterials 28: 2622-2630.

Zapata P, Su J, Garcia AJ, Meredith JC (2007) Quantitative high-throughput screening of osteoblast attachment, spreading, and proliferation on demixed polymer blend micropatterns. Biomacromolecules 8: 1907 1917.

Zhang L, Li P, Gong Z, Li X (2008) Photocatalytic degradation of polycyclic aromatic hydrocarbons on soil surfaces using TiO(2) under UV light. J Hazard Mater 158: 478-484.

Zhang Z, Wang K, Bai C, Li X, Dang X, Zhang C (2012) The influence of UV irradiation on the biological properties of MAO-formed $\mathrm{ZrO}_{2}$. Colloids Surf B Biointerfaces 89: 40-47.

Zubkov T, Stahl D, Thompson TL, Panayotov D, Diwald O, Yates JT, Jr. (2005) Ultraviolet light-induced hydrophilicity effect on $\mathrm{TiO}_{2}(110)(1 \times 1)$. Dominant role of the photooxidation of adsorbed hydrocarbons causing wetting by water droplets. J Phys Chem B 109: 1545415462 . 


\section{Discussion with Reviewers:}

Masahiro Yamada: What do authors think about the mechanism underlying photofunctionalisation on $\mathrm{ZrO}_{2}$ surface?

Authors: The term 'photofunctionalisation' has previously been described as the effect of UV light on titanium surfaces. The photochemical and photocatalytic removal of hydrocarbons from the titanium surfaces, the generation of hydrophilicity and a modification of the surface electrostatic properties were reported as consequences of this irradiation (Aita et al., 2009b; Att et al., 2009a; Att et al., 2009b; Att et al., 2009c; Iwasa et al., 2010).

The change in the wettability behaviour of oxides of $\mathrm{Ti}$ and Ti alloys upon UV light treatment were attributed to the electrostatic properties of $\mathrm{TiO}_{2}$ and its high photocatalytic activity (Aita et al., 2009b; Att et al., 2009a; Att and Ogawa, 2012; Iwasa et al., 2010). Accordingly, UV irradiation induces a temporal chemical alteration within the superficial layer of $\mathrm{TiO}_{2}$, resulting in a photocatalytic chemical reaction (Han et al., 2008; Wang et al., 1997) by the excitement of electrons from the valence to conduction band (Wang et al., 1997; Zubkov et al., 2005). This leads to a decomposition of native organic contaminants on the surface of $\mathrm{TiO}_{2}$ (Aita et al., 2009b; Att et al., 2009a; Att et al., 2009b; Att et al., 2009c; Iwasa et al., 2010), transforms the negatively charged superficial $\mathrm{TiO}_{2}$ layer to electropositive (Iwasa et al., 2010) and significantly alters the wettability property of the surface from hydrophobic to hydrophilic (Ghicov and Schmuki, 2009; Takeuchi et al., 2005b; Zubkov et al., 2005). Furthermore, it has been suggested that the surface oxygen vacancies can be formed at bridging sites, resulting in the conversion of $\mathrm{Ti}^{4+}$ sites to $\mathrm{Ti}^{3+}$, which are favourable for dissociative water adsorption (Wang et al., 1997). Compared to titanium, zirconia is an insulating oxide material with a relatively wide band gap, meaning that electrons also can be excited from the valence band to the conduction band by UV treatment provided the photon energy is sufficient (Ghicov and Schmuki, 2009). It is noteworthy to mention that the zirconia requires photon energy larger than $5 \mathrm{eV}$ to cause electrons to go from the $\mathrm{V}$ to $\mathrm{C}$ band to express its photocatalytic activity, whereas the energy required for titanium oxide is around $3.2 \mathrm{eV}$ (Att et al., 2009c; Ghicov and Schmuki, 2009).

The amount of surface carbon detected on the tested zirconia surfaces and its removal by UV treatment is also similar to titanium surfaces (Aita et al., 2009b; Att et al., 2009a). The atomic percentage of carbon decreased substantially upon UV treatment, whereas the amount of other elements uniformly increased according to the reduction of superficial hydrocarbons (Aita et al., 2009a; Aita et al., 2009b; Att et al., 2009a). Two mechanisms are suggested for the removal of surface carbons by UV treatment on titanium and probably can be applied to zirconia as well. The first mechanism is direct decomposition of carbon molecules per se by UV light, and the second mechanism relates to the photocatalytic activity of zirconia (Aita et al., 2009b; Takeuchi et al., 2007; Takeuchi et al., 2005b). In terms of the different capacities of UVA (315-380 nm) and UVC (100-280 nm) for removing surface carbons, UVC is generally capable of a direct photodecomposition of organic components, whereas UVA removes carbons by its photocatalysis (Shie et al., 2008; Wong and Chu, 2003; Zhang et al., 2008). The band gap for the zirconia however requires UV of shorter wavelengths than those used to irradiate the surfaces in this study, which suggests that such a mechanism probably does not play a major role. Instead, it would appear that the UV energy is sufficient to break the relatively weak adhesion between the hydrocarbons and carbonate ions that are absorbed on the surface.

It is suggested that the observed alterations in the physicochemical properties of zirconia upon UV treatment can be attributed to similar mechanisms proposed for titanium surfaces but with a greater likelihood of being associated with photodecomposition.

Masahiro Yamada: How does the elemental composition of $\mathrm{ZrO}_{2}$ influence the reactivity to photofunctionalisation? Authors: In comparison to the more conventional yttrium tetragonally stabilised zirconium oxide samples $\mathrm{Zr} 2$ (93 wt $\% \mathrm{ZrO}_{2}, 5 \mathrm{wt} \% \mathrm{Y}_{2} \mathrm{O}_{3}, 1.9 \mathrm{wt} \% \mathrm{HfO}_{2}$ and $0.1 \mathrm{wt} \%$ $\mathrm{Al}_{2} \mathrm{O}_{3}$ ), the zirconia samples of $\mathrm{Zr} 1$ contained less $\mathrm{ZrO}_{2}$ $(85.7 \mathrm{wt} \%)$ and $\mathrm{Y}_{2} \mathrm{O}_{3}(4.3 \mathrm{wt} \%)$ but more $\mathrm{Al}_{2} \mathrm{O}_{3}(8.3 \mathrm{wt} \%)$ and even additional $\mathrm{La}_{2} \mathrm{O}_{3}(1.7 \mathrm{wt} \%)$.

A possible effect of additional elements on the UV effect cannot be excluded. However, within the scope of this work, neither, SEM, AFM, XPS nor contact angle measurements revealed any difference in the reactivity to the UV irradiation.

Masao Yoshinari: It is recommended that the authors express the opinion about the other hydrophilic treatments such as acid-etching and cold-plasma treatments in addition to the UV treatment.

Authors: Available literature shows that the mentioned surface applications can also have positive effects on the cell-biologic activity. Here, one of the most recent studies (Watanabe et al., 2012) can be considered to provide a good survey of the effect of the mentioned surface modification techniques. The results of this study underline and complement the findings of our study. The authors examined the effect of different hydrophilic treatments on the surface characteristics and the bioactivity of tetragonal zirconia polycrystals (TZP). They compared four different surface treatment methods, comprising application of cells immediately after sandblasting and acid-etching, oxygen plasma and UV light against control specimens stored in air (aged surfaces). The results indicated that surface sandblasting and acid-etching, plasma application and UV light induced a superhydrophilic surface and decreased enormously surface contents. To follow the biological effect, an enhanced initial attachment of the used osteoblast-like cells could be observed.

Ansgar Petersen: Since the adsorption of plasma proteins is known to be crucial in implant response, it would be helpful to include the aspect of protein adsorption on the differently treated surfaces in the discussion. How large is the effect on cell attachment and proliferation expected to be if the different materials were exposed to plasma proteins before seeding? 
Authors: The capacity for protein adsorption is a critical component in determining the biocompatibility and bioactivity levels of implantable materials (Woo et al., 2007). Through the interaction between integrins and adsorbed proteins, cells attach to the biomaterial surface. The degree of this interaction consequently affects the spreading, proliferation, and differentiation of the cells (Hori et al., 2009; Mata et al., 2003). Recent in vitro investigations showed that UV-treated titanium surfaces increased protein adsorption and attachment, proliferation, differentiation, and mineralisation of osteogenic cells (Aita et al., 2009b; Att et al., 2009a). Another study revealed that osteoblast adhesion was established faster and stronger on UV-treated titanium surfaces being supported by an increased expression of focal adhesion protein vinculin (Iwasa et al., 2010). Therefore, the authors believe that exposing the different materials to plasma proteins before seeding would have a further enhancing impact on cell biologic activity of the surfaces.

Ansgar Petersen: It is surprising that the surface treatment leads to opposite effects concerning ALP-Activity on Zr1-m vs. Zr2-m at day 7 (Fig. 5c). What do the authors think is the reason for this?

Authors: The different chemical compositions and/or the surface topographies of the used specimens can be possible reasons for these results. 